\title{
Ontogenetic habitat use in labrid fishes: an ecomorphological perspective
}

\author{
Christopher J. Fulton*, David R. Bellwood
}

Centre for Coral Reef Biodiversity, Department of Marine Biology, James Cook University, Townsville, Queensland 4811, Australia

\begin{abstract}
We examined the extent to which wave exposure and swimming ability shape the ontogenetic distribution patterns of wrasses across the Great Barrier Reef at 2 spatial scales: cross-shelf and within-habitat. Visual censuses were used to record the distribution of juveniles and adults among shelf habitats, and their relative position in the water-column within a single, wave-swept habitat zone. Pectoral fin shape was used as a measure of swimming ability. Examination of fins from a broad size range of individuals indicated an ontogenetic shift in swimming ability in 5 of the 8 species examined. Despite apparent differences in their swimming abilities, juveniles and adults of each species displayed similar distributions across the 11 shelf habitats. Significant differences in habitat distributions were only apparent among species. Microhabitat use within the reef flat, however, displayed a distinct trend of increasing water-column use with increasing size in those 5 species that displayed a marked ontogenetic shift in swimming ability. This shift in microhabitat use appeared to be due largely to flow-refuging behaviour in the small individuals and slow-swimming species.
\end{abstract}

KEY WORDS: Ontogeny · Ecomorphology · Habitat use · Labridae · Locomotion · Coral reefs · Swimming ability

Resale or republication not permitted without written consent of the publisher

\section{INTRODUCTION}

Numerous studies on the distribution and abundance of coral reef fishes have provided evidence for both recruitment and post-recruitment processes in shaping reef fish communities (Jones 1991). Several biological factors have been identified, including behavioural selectivity at settlement, predation, competition and migration (Jones 1991, Williams 1991). Despite being a conspicuous physical feature of coral reefs, wave energy has received comparatively little attention in reef fish studies. Although studies have often identified a correlation between wave exposure and the distribution patterns of reef fishes (Williams 1982, Russ 1984, Green 1996), only recently has a possible basis for these correlations been provided. Following the elucidation of a diversity of swimming abilities in the family Labridae (Wainwright et al. 1999,

*E-mail: christopher.fulton@jcu.edu.au
2002, Walker \& Westneat 2000, 2002), strong correlations between the degree of wave exposure of habitats and the swimming abilities of resident species have been reported (Bellwood \& Wainwright 2001, Fulton et al. 2001). These studies hypothesised that habitats with high water movement may require individuals to maintain higher swimming speeds, versus slow-speed manoeuverability in low water-movement habitats, in order to accomplish daily activities. Those species which are not capable of efficiently sustaining high swimming speeds may therefore be disadvantaged, and consequently display lower abundance or be absent from exposed reef habitats (Bellwood \& Wainwright 2001, Fulton et al. 2001).

Although patterns of labrid swimming ability and distribution have been established among species, little is known of the variation within species. Pectoral fin aspect-ratio is a simple morphological measure which has been demonstrated to be a reliable predictor of swimming ability in labrids (Wainwright et al. 1999, 2002, Walker \& Westneat 2000, 2002). Species within 
the family exhibit a continuum between the 2 extremes of low aspect-ratio fins, which indicate primarily dragbased thrust, versus high aspect-ratio fins, which are primarily used for lift-based thrust, the latter producing faster swimming speeds for a given size (Vogel 1994, Wainwright et al. 2002, Walker \& Westneat 2002). A similar functional continuum in pectoral fin morphology may be expected also to exist throughout ontogeny, particularly in those species which exhibit high aspect-ratio pectoral fins as adults.

Given that adult labrids exhibit species-specific differences in their habitat use which are related to their swimming ability and the wave regime of habitats, an ontogenetic shift in abilities may also be expected to be reflected in an ontogenetic shift between habitats of different wave exposure. Although some labrids have previously been found to settle and recruit directly into adult habitats (Eckert 1984), ontogenetic migrations between habitat zones have also been recorded in labrids (Green 1996), and are well documented for other reef fishes (Williams 1991). Studies in freshwater systems also suggest that fishes displaying an ontogenetic shift in locomotor morphology also exhibit a concurrent shift from slow- to fast-flowing habitats (Sagnes et al. 1997, Simonovic et al. 1999). One may therefore predict that labrid species which show an ontogenetic shift in locomotor morphology will also exhibit a shift in habitat use from sheltered to more exposed locations.

Processes operating at smaller spatial scales, such as within habitat zones, have often provided crucial insight into broader-scale patterns. Reef fishes with specific microhabitat requirements have been found to be restricted in their broad-scale distribution and abundance by the presence of a required substratum type (Bell \& Galzin 1984, Munday et al. 1997, Munday 2000). Habitat selectivity during settlement appears, in many labrid species, to be driven largely by microhabitat type, regardless of depth (Eckert 1985). Furthermore, expected distributions of adult labrids across habitat zones, based on their swimming ability, were found to be modified by behavioural use of the watercolumn within wave-swept habitat zones (Fulton et al. 2001). Use of substratum complexity and boundarylayer effects as refuges from water flow was suggested to be a mechanism by which slow-swimming species were able to persist in high wave-energy habitats (Bellwood \& Wainwright 2001, Fulton et al. 2001). Similar examples of this mechanism have been reported for the ontogenetic distribution of stream fishes (Sagnes et al. 1997, Simonovic et al. 1999), and may also operate for juvenile labrids on coral reefs.

Could wave energy be structuring fish assemblages not only among species, but also within species? This study aims to examine the relationship between ontogeny of fin morphology and habitat use in labrids.
Firstly, we examine ontogeny in the locomotor morphology of 8 labrid species, which were selected for their abundance and diversity of swimming abilities as adults (Bellwood \& Wainwright 2001). Secondly, we examine the distribution of these species across the continental shelf of the Great Barrier Reef. Specifically we examine the extent to which: (1) there are differences in the distribution of adults and juveniles among habitat zones of differing wave energy, and (2) these patterns are correlated with changes in size and inferred swimming ability. Finally, we examine the extent to which microhabitat (water-column) use by labrids within a high wave-energy habitat zone reflects differences in size and inferred swimming abilities during ontogeny.

\section{MATERIALS AND METHODS}

Fin morphology. For morphological examination of pectoral fins, a broad size range of individuals (3 to $20 \mathrm{~cm}$ total length, divided into 6 size classes, mean $4.8 \pm 1.9 \mathrm{SE}$ in each size class) from each of the 8 species were collected by spear and barrier net from the reefs around Lizard Island, Great Barrier Reef, Australia, between January 2000 and January 2001. Pectoral fins were removed at the base as near to the body as possible, then spread but not stretched on a sheet of foam, pinned, and then fixed in position with 100\% formalin. A digital image was taken and analyzed using ScionImage (v4.0.2, Scion Corporation) to measure the length of the leading edge and the total fin area (following Fulton et al. 2001). Pectoral fin shape was then expressed as an aspect-ratio, which is calculated as: leading edge ${ }^{2}$ area $^{-1}$

Fish censuses. Censusing of among-habitat distributions was conducted between November 1998 and February 1999 on the northern section of the Great Barrier Reef, with 3 reefs censused at each of the crossshelf locations of inner, mid and outer shelf. Within each reef, 4 habitats were censused: slope, crest, flat and back habitat zones (site details in Bellwood \& Wainwright 2001), with the exception of the inner shelf which lacked a distinct crest. These locations were chosen to encompass both cross-shelf and within-reef gradients of wave exposure. Each census consisted of two 20 min timed swims parallel to the reef crest (modified after Bellwood 1996). One observer identified and recorded all labrids $>10 \mathrm{~cm}$ total length (TL) within a $5 \mathrm{~m}$ wide transect (estimated by comparison with a tape at the beginning of the transect). A second observer recorded all small labrids $(<10 \mathrm{~cm}$ TL) within a $1 \mathrm{~m}$ wide transect, taking particular care to locate cryptic individuals. Fish total lengths were estimated in $2.5 \mathrm{~cm}$ size-classes if $<10 \mathrm{~cm} \mathrm{TL}$, and $5 \mathrm{~cm}$ size- 
classes if $>10 \mathrm{~cm}$ TL. Four censuses were conducted in each habitat zone, on each reef, with a minimum of $20 \mathrm{~m}$ separating adjacent censuses. Juveniles were defined as $>25 \mathrm{~mm}$ TL (the smallest size censused), and $<30 \%$ of the maximum TL stated in Randall et al. (1997), with the exception of Gomphosus varius (juveniles $<6 \mathrm{~cm}$ TL). The area censused in each timed swim was determined using differential GPS (Garmin 12XL, with CSI ABX-3 beacon receiver) to estimate the distance between surface buoys placed at the start and finish of each transect. Trials indicated that these distances were accurate to within $5 \mathrm{~m}$, with an average transect length of $235 \mathrm{~m}( \pm 55.5 \mathrm{SE}, \mathrm{n}=132)$. This method allowed for a rapid collection of census data while minimising observer effects (Bellwood \& Wainwright 2001).

Censusing of microhabitat use (water-column distributions) was conducted during September to October 1999 on the reef flat of 2 fringing reef sites on the NE aspect of Lizard Island (site details in Fulton et al. 2001). Following a non-overlapping path over the reef flat, a focal individual census technique was used to record species, total length, and vertical height above the substratum, as each labrid individual was encountered. Lengths were estimated to the nearest $1 \mathrm{~cm}$, distances to the nearest $5 \mathrm{~cm}$. This was repeated until a minimum of 80 observations were obtained for each site for each of the 8 labrid species. Individuals spanned the same size range as those obtained for the fin morphology examinations.

Analyses. Pectoral fin morphology and fish length relationships were examined for each species using least-squares linear regressions of pectoral fin aspectratio against log total length. These regressions were then compared by ANCOVA analysis and GT2 multiple comparison of slopes to determine any major groupings among species (Sokal \& Rohlf 1995).

Cross-shelf censuses were standardised to individuals $100 \mathrm{~m}^{-2}$ to account for differences in transect length and width (1 or $5 \mathrm{~m}$ ), and then pooled at the level of habitat. Due to the order of magnitude difference between juvenile and adult densities, densities are expressed as proportional values to compare the relative distribution of juveniles vs adults across shelf habitats. These proportions were calculated for each species by dividing the number of individuals present in each shelf habitat by the total number of individuals across all 11 shelf habitats, for 3 transects across the shelf, for each stage of maturity (juvenile/adult). An arcsine transformation following Freeman \& Tukey (1950) was performed to remove sig- nificant departures from normality (Zar 1984), and this was verified by the Kolmogorov-Smirnov normality test on each variable and factor combination (all $\mathrm{p} \geq 0.06$ ). Two-way multivariate analysis of variance (MANOVA) was then performed on the transformed proportional data, with 11 cross-shelf habitats and 2 maturity stages (juvenile/adult) as fixed factors.

Microhabitat (water-column) use and size relationships for each species, at each site, were examined using least-squares linear regression following log-log transformation. Site effects were determined by separate 1-way ANCOVAs performed on the regressions of total length against height in the water-column from each site for each of the 8 species. Following a result of no site effect with significances of $p>0.2$ for each species, water-column use data from each site were pooled for each species following Winer (1971). An $F$-test comparing the slopes of the pooled regression equations from the 8 species was then performed, followed by a GT2 multiple comparison of regression coefficients (Sokal \& Rohlf 1995).

\section{RESULTS}

\section{Fin ontogeny}

Significant ontogenetic changes were found in the 8 species examined, with the degree of change in pectoral fin shape and size varying among species (Table 1, Fig. 1). Significant differences between the regression coefficients of each species were evident from ANCOVA analysis $(F=21.54$, df $=7,141, \mathrm{p}<$ 0.001 ), with post-hoc multiple comparisons identifying 2 significant groups (Table 1, Fig. 2). These groups separate the species which display a high fin aspectratio as adults (Figs. 1A \& 2A) from those species with markedly lower fin aspect-ratios at equivalent sizes (Figs. 1B \& 2B). The greatest ontogenetic changes in fin shape were seen in those species which displayed

Table 1. Regression coefficients (slopes), ANOVA results testing significance of regressions, and GT2 post-hoc groupings of the relationship between fin aspectratio and size for 8 labrid species

\begin{tabular}{|lcccc|}
\hline Species & $\begin{array}{c}\text { Regression } \\
\text { coefficient }(\mathrm{b})\end{array}$ & $F\left(\mathrm{df}_{1}, \mathrm{df}_{2}\right)$ & $\mathrm{p}$ & $\begin{array}{c}\text { GT2 post- } \\
\text { hoc groups }\end{array}$ \\
\hline Thalassoma amblycephalum & 2.20 & $145.56(1,16)$ & $<0.001$ & $\mathrm{~A}$ \\
Thalassoma jansenii & 1.77 & $180.09(1,30)$ & $<0.001$ & $\mathrm{~A}$ \\
Thalassoma hardwicke & 1.76 & $97.86(1,17)$ & $<0.001$ & $\mathrm{~A}$ \\
Gomphosus varius & 2.23 & $126.45(1,16)$ & $<0.001$ & $\mathrm{~A}$ \\
Halichoeres marginatus & 1.31 & $34.697(1,14)$ & $<0.001$ & $\mathrm{~A}$ \\
Halichoeres margaritaceus & 0.64 & $14.53(1,8)$ & 0.005 & $\mathrm{~B}$ \\
Halichoeres melanurus & 0.42 & $6.09(1,15)$ & 0.026 & $\mathrm{~B}$ \\
Hemigymnus melapterus & 0.24 & $9.05(1,25)$ & 0.006 & $\mathrm{~B}$ \\
\hline
\end{tabular}




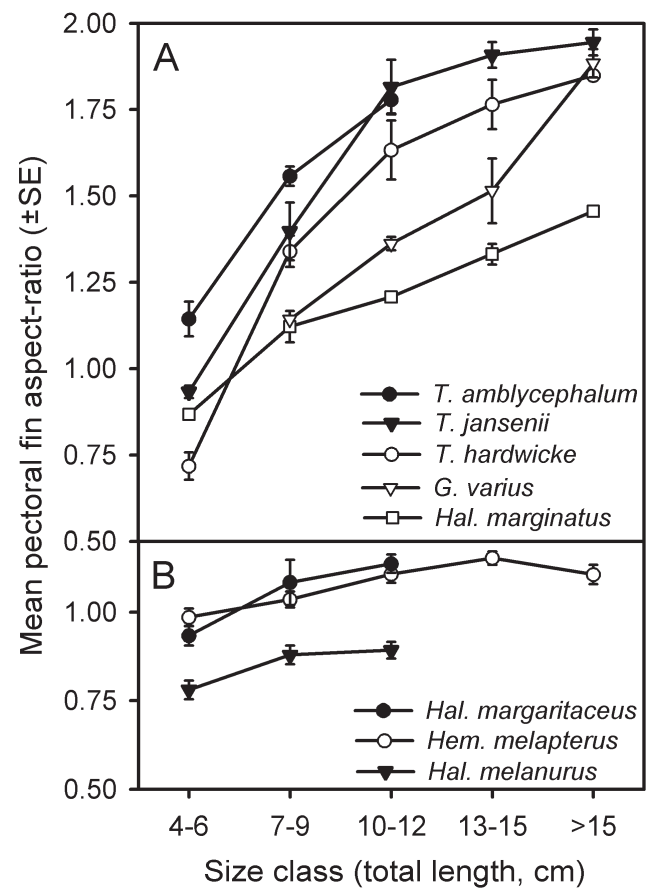

Fig. 1. Relationship between size and pectoral fin aspect-ratio for 8 species of labrids, divided into 2 groups (A and B) according to post-hoc comparison of regression coefficients (Table 1). Mean aspect-ratios are calculated from individuals in each size class. Full specific names as in Table 1

the highest fin aspect-ratios (>1.4) as adults: Thalassoma amblycephalum, T. jansenii, T. hardwicke, Gomphosus varius and Halichoeres marginatus (Fig. 1A). With 1 exception, T. amblycephalum, all species, regardless of adult fin aspect-ratio, displayed a similarly low aspect-ratio $(<1.0)$ at the smallest size range examined (Fig. 1). T. amblycephalum displayed a high fin aspect-ratio even at this smallest size range (Fig. 1A).

\section{Cross-shelf and microhabitat-use patterns}

Collectively, species displayed significant differences in their among-habitat distributions (Table 2). Individually, species with adults of high fin aspect-ratio were distributed primarily towards the outer shelf and in habitats with high incident wave energy, whereas the low aspect-ratio species were distributed toward the inner shelf and/or habitats of moderate to low wave exposure (Fig. 3). Although a significant difference in distributions among habitats was detected, no significant differences were found among maturity stages (Table 2). Adults and juveniles of each species displayed similar proportional distributions among habitat zones across the shelf, with no significant differ-
Table 2. Results of 2-way multivariate ANOVA comparing the proportional distribution of 2 maturity stages (juvenile/adult) among 11 cross-shelf habitats for 8 labrid species

\begin{tabular}{|lcccr|}
\hline Factor & Pillai's trace & $F$ & $\mathrm{df}$ & \multicolumn{1}{c|}{$\mathrm{p}$} \\
\hline Maturity & 0.09 & 0.47 & 8,37 & 0.872 \\
Habitat & 5.25 & 8.40 & 80,352 & $<0.001$ \\
Maturity $\times$ Habitat & 1.68 & 1.17 & 80,352 & 0.178 \\
\hline
\end{tabular}

ence found between maturity for all species, and no significant interaction (Table 2).

Significant ontogenetic changes in water-column use were found in all species, with the increase in water-column use during ontogeny varying among species (Table 3, Fig. 4). No significant site effect was identified by ANCOVA analysis on each of the 8 species censused (Table 4). Regressions of the pooled data (at the level of site for each species) were found to be significantly different between species by an $F$-test comparing their slopes $(F=25.45$, df $=7,2054$, $\mathrm{p}<0.001)$. Multiple comparisons revealed no distinct groups, with species grouped singly or in pairs on a continuum between those with high (Fig. 4A) and those with low (Fig. 4B) aspect-ratio adults, with the exception of Gomphosus varius (Table 3). All species exhibited a similarly restricted use of the water column (less than $10 \mathrm{~cm}$ above the substratum) at sizes from 0 to $9 \mathrm{~cm}$ total length (TL) (Fig. 4). Differences between species in water-column use with size arose at $9 \mathrm{~cm}$ TL or greater (Fig. 4), except for Thalassoma amblycephalum, which markedly increased water-column use at $7 \mathrm{~cm}$ TL. With 1 exception, G. varius, the greatest increase in water-column use during ontogeny was found in those species with high fin-aspect ratios (>1.4) as adults (Fig 4A).
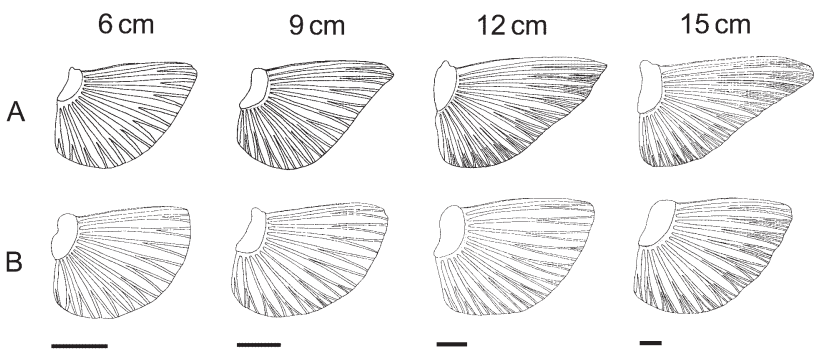

Fig. 2. Illustrations of pectoral fin shape through ontogeny in representatives of the 2 major groups identified by post-hoc analyses. (A) Thalassoma hardwicke: example of a species that displayed an increase in aspect-ratio with increasing size; (B) Hemigymnus melapterus: example of a species that exhibited relatively little change in fin shape with increasing size. Bars indicate $5 \mathrm{~mm}$ scale for fins in each size category 
Table 3. Regression coefficients (slopes), ANOVA results testing significance of regressions, and GT2 post-hoc groupings of the relationship between watercolumn use and size for 8 labrid species, pooled at the level of site

\begin{tabular}{|lcrcc|}
\hline Species & $\begin{array}{c}\text { Regression } \\
\text { coefficient }(\mathrm{b})\end{array}$ & $F\left(\mathrm{df}_{1}, \mathrm{df}_{2}\right)$ & $\mathrm{p}$ & $\begin{array}{c}\text { GT2 post- } \\
\text { hoc groups }\end{array}$ \\
\hline Thalassoma hardwicke & 2.19 & $306.58(1,325)$ & $<0.001$ & $\mathrm{~A}$ \\
Thalassoma amblycephalum & 1.72 & $264.08(1,179)$ & $<0.001$ & $\mathrm{~B}$ \\
Thalassoma jansenii & 1.78 & $247.33(1,331)$ & $<0.001$ & $\mathrm{~B}$ \\
Gomphosus varius & 0.79 & $42.53(1,253)$ & $<0.001$ & $\mathrm{D}$ \\
Halichoeres marginatus & 1.85 & $101.33(1,170)$ & $<0.001$ & $\mathrm{C}$ \\
Halichoeres margaritaceus & 1.42 & $115.53(1,319)$ & $<0.001$ & $\mathrm{C}$ \\
Halichoeres melanurus & 0.74 & $44.14(1,283)$ & $<0.001$ & $\mathrm{D}$ \\
Hemigymnus melapterus & 0.71 & $63.17(1,194)$ & $<0.001$ & $\mathrm{D}$ \\
\hline
\end{tabular}

\section{DISCUSSION}

Marked changes in pectoral fin morphology through ontogeny were evident in 5 of the 8 species examined, namely those which display a high pectoral fin aspect-ratio as adults. When small (4 to $6 \mathrm{~cm}$ total length), all species display a similarly low pectoral fin aspect-ratio. Five species displayed an increase in fin aspect-ratio with increasing size, spanning values of 0.75 to 1.95 throughout ontogeny. This within-species range is comparable to the full spectrum of pectoral fin morphologies displayed among species in the family (Wainwright et al. 2002, Walker \& Westneat 2000, 2002). In functional terms, this means that the smaller juveniles possess a fin morphology indicative of predominantly dragbased thrust, which is usually associated with slow sustained swimming speeds, compared to the higher aspect-ratio adult fin morphology which is indicative of lift-based thrust and faster swimming speeds for a given size (Vogel 1994, Wainwright et al. 2002, Walker \& Westneat 2000, 2002). This apparent lack of evidence for lift-based thrust at small body sizes is consistent with physical considerations which suggest that such thrust is mechanically inefficient at these small sizes (Webb \& Weihs 1986, Vogel 1994).

For the 5 species with the greatest ontogenetic change, Thalassoma amblycephalum, T. hardwicke, T. jansenii, Gomphosus varius and Halichoeres marginatus, their fin morphology suggests that the juveniles have a reduced swimming ability compared to the adults. Conversely, the 3 remaining species, Hemigymnus melapterus, Halichoeres melanurus and $H$. margaritaceus, displayed little change in fin aspectratio with size, with relatively constant values between 0.75 and 1.2 , reflecting a similar swimming ability regardless of size or maturity. These aspect-ratios indicate the predominant swimming mode used by indi-

Table 4. Results of 1-way ANCOVA examining site effects in water-column use with size for each of the 8 labrid species

\begin{tabular}{|lccc|}
\hline Species & $\mathrm{df}$ & $F$ & $\mathrm{p}$ \\
\hline Thalassoma amblycephalum & 1,179 & 0.03 & 0.861 \\
Thalassoma jansenii & 1,331 & 0.09 & 0.761 \\
Thalassoma hardwicke & 1,325 & 0.43 & 0.511 \\
Gomphosus varius & 1,253 & 1.50 & 0.222 \\
Halichoeres marginatus & 1,170 & 0.01 & 0.924 \\
Halichoeres margaritaceus & 1,319 & 0.07 & 0.799 \\
Halichoeres melanurus & 1,283 & 0.13 & 0.717 \\
Hemigymnus melapterus & 1,194 & 0.01 & 0.950 \\
\hline
\end{tabular}

Fig. 3. Distribution and mean abundance of juveniles (open bars) and adults (closed bars) across 11 cross-shelf habitats $(\mathrm{n}=3)$ for 8 labrid species. Estimations of relative wave energy incident in each habitat zone are indicated, expressed as a percentage of wave energy incident on the outer shelf reef flat (after Bellwood \& Wainwright 2001). S/Crest: slope/crest 


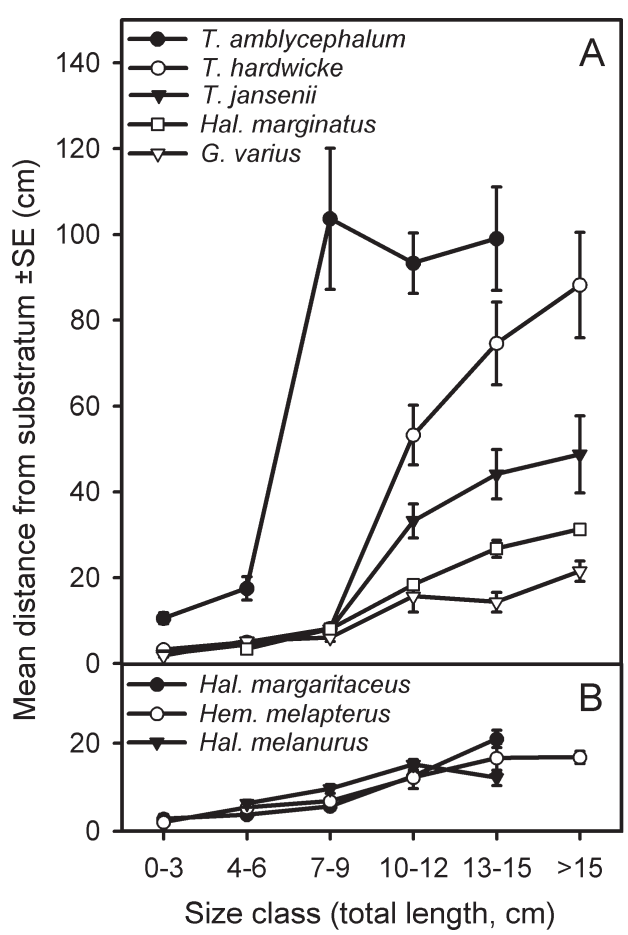

Fig. 4. Relationship between size and water-column position, expressed as mean distance from substratum for each size class, for 8 species of labrids. Species are divided into 2 groups (A and B) according to post-hoc analysis of pectoral fin ontogeny for direct comparison (see Table 1, Fig. 1). Full specific names as in Table 1

viduals, which impacts on the relative swimming speeds that can be efficiently sustained for a given size (Vogel 1994, Wainwright et al. 2002, Walker \& Westneat 2002, but see Drucker \& Jensen 1996). Size itself is also important for the actual speeds achieved in fishes, with smaller individuals exhibiting slower actual speeds compared to larger conspecifics (Vogel 1994). Ultimately, this implies that for those species which show a dramatic shift in fin morphology, the shift in actual swimming speeds between juvenile to adult is considerably more dramatic than in those species which lack such a shift in fin morphology.

Contrary to expectations that an ontogenetic shift in swimming abilities would coincide with an ontogenetic shift in distributions, no differences in among-habitat use were observed between the juveniles and adults of each species. The greatest abundance of juveniles were located in the same habitat zone as the greatest abundance of adults, for all species examined. This is despite the fact that those species that displayed a pronounced change in fin morphology through ontogeny (suggesting differential swimming ability between maturity stages) also tended to occur predominantly in high wave-energy habitats and/or shelf locations. Such locations would be expected to be most disadvantageous for their slower swimming juveniles, compared to other habitat zones, due to the higher sustained swimming speeds generally associated with daily activities in these locations. Regardless of the apparent disadvantages, it appears that these juveniles spend a large proportion of the juvenile phase in the adult habitat, i.e. zones of high wave energy. Indeed, many appear to recruit directly to these locations (C. J. Fulton \& D. R. Bellwood pers. obs.), perhaps as a result of gregarious settlement (Eckert 1984).

Matching juvenile-adult distributions, despite indications that swimming abilities differ between maturity stages in some species, suggests that ontogenetic distribution patterns may not be a direct result of wave energy. Given that many labrids have been found to settle in non-adult habitats (Eckert 1985) and undergo post-recruitment migrations between habitat zones (Green 1996), the potential for migration during ontogeny does exist. Why then, is migration not used by these species as a mechanism to avoid such apparently disadvantageous conditions? Is there another mechanism operating which ameliorates the impact of wave energy on these juvenile individuals? Microhabitat use of the water-column appears to be one such mechanism, with water-column use by these species showing clear ontogenetic trends. These species-specific patterns of water-column use were congruent with the different ontogenetic development of fin morphologies. Those species which displayed marked changes in fin shape with growth likewise displayed an increase in water-column use with increasing size, with juveniles less than $20 \mathrm{~cm}$ above the substratum compared to an average of up to $100 \mathrm{~cm}$ in the adults (Fig. 5). Stream fishes exhibit a similar ontogenetic distribution pattern, remaining in close proximity to the substratum at small sizes, with movement towards higher flow, mid-stream locations with increasing size (Sagnes et al. 1997, Simonovic et al. 1999). Remaining close to the substratum may indicate refuging behaviour, involving use of the boundary layer and substratum structures as water flow refuges (Vogel 1994, Gerstner 1998, Gerstner \& Webb 1998). Use of this reduced flow adjacent to the substratum avoids the need for excessive swimming activity to maintain station and conduct daily activities (Vogel 1994, Webb 1994, Gerstner 1998). Such a behavioural mechanism would thus allow the juveniles to avoid the disadvantages associated with high wave-energy habitats and alleviate the need for ontogenetic migrations between habitats. Ontogenetic migrations by these species do occur in response to wave energy, but are manifest at the smaller scale of within habitats (i.e. distance from the substratum), rather than between habitats (Fig. 5). 


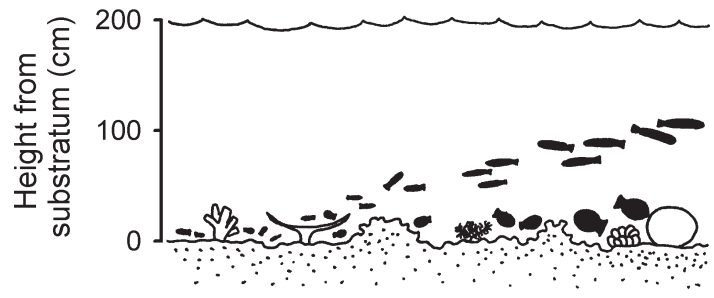

Fig. 5. Schematic illustration of ontogenetic water-column use in the 2 major groups found in this study: the elongate fish represent those species which exhibited a marked increase in pectoral fin aspect-ratio with increasing size, the deep-bodied fish represent species which exhibited relatively little change in pectoral fin aspect-ratio with growth

Maintaining close proximity to the substratum has other advantages. Given that the most dramatic shift in water-column use occurs around a similar size range (10 to $12 \mathrm{~cm}$ total length) for most of the species observed, size-dependent predation risk may also be important. Juveniles of most reef fishes tend to occur in close proximity to the substratum, probably as a mechanism to avoid predation by maintaining quick access to refuges (Hixon \& Beets 1993). Several experiments in freshwater systems have demonstrated that restricted habitat use by juvenile sunfishes was due to size-related predation risk (Mittelbach 1981, Werner et al. 1983, Werner \& Hall 1988). However, minimal use of the water-column was not restricted to juveniles. Those species which did not exhibit a major shift in fin morphology with size, but maintained a low aspectratio (indicating slow sustained swimming speeds) throughout ontogeny, also exhibited a similarly restricted water-column use, even at adult sizes (Fig. 5). This suggests that size-related predation risk is not the only mechanism operating and lends support to the suggestion that swimming ability may be the major constraining factor in such locations.

It is interesting to note that there is strong congruence between among-species and within-species patterns of water-column use. Labrid species which have an average adult fin aspect-ratio of $>1.55$ tend to use the water column more extensively than species with lower aspect-ratio fins (Fulton et al. 2001). Similarly, in those species which exhibit an increase in water-column use with growth, the size at which the most dramatic increase occurs (10 to $12 \mathrm{~cm}$ total length) corresponds to when a mean aspect-ratio of around 1.4 to 1.6 is obtained. It is also noteworthy that Thalassoma amblycephalum reaches this fin morphology at a smaller size ( 7 to $9 \mathrm{~cm}$ total length) than the other species examined, and concurrently exhibits an increase in water-column use at this smaller size. One major exception to this general trend is Gomphosus varius which, despite reaching a high average aspect-ratio value of 1.78 at the largest size examined, displayed a similar degree of water-column use as those slower swimming adults with much lower maximum aspectratios. This represents a case in which the potential for a species to use the water-column exists, but is not realized. Rather, it appears that this species uses such locomotor abilities to travel large horizontal distances during short-term foraging forays (Fulton \& Bellwood 2002).

Previously it has been difficult to discriminate between the relative importance of biological and physical factors in labrid distributions, largely due to a lack of adequate information on the post-recruitment ecology of labrids, apart from indications that ontogenetic migrations (Green 1996) and estimated adult swimming abilities may be important (Bellwood \& Wainwright 2001, Fulton et al. 2001). The evidence presented herein suggests that both biological and physical aspects may be important. Numerous studies have identified a host of biological factors modifying recruitment and post-recruitment patterns in reef fishes, including predation, food availability and competition (Jones 1991, Williams 1991). This study emphasizes the potential for non-biological factors to have a significant impact on both recruitment patterns and post-recruitment behaviour, and possibly evolutionary fitness. Physical factors are often regarded as important for invertebrates on coral reefs (particularly corals); this work emphasizes the potential impact of physical factors on other more mobile coral reef taxa, including fishes.

Acknowledgements. We wish to thank P. Donovan, C. Fallea, A. Thomas and the staff at Lizard Island Research Station for their field support. Thanks also to A. Hoey, M. Marnane and P. C. Wainwright for helpful discussions. Supported by the Australian Research Council (D.R.B.).

\section{LITERATURE CITED}

Bell JD, Galzin R (1984) Influence of live coral cover on coralreef fish communities. Mar Ecol Prog Ser 15:265-247

Bellwood DR (1996) The Eocene fishes of Monte Bolca: the earliest coral reef fish assemblage. Coral Reefs 15:11-19

Bellwood DR, Wainwright PC (2001) Locomotion in labrid fishes: implications for habitat use and cross-shelf biogeography on the Great Barrier Reef. Coral Reefs 20: 139-150

Drucker E, Jensen J (1996) Pectoral fin locomotion in the striped surfperch. II. Scaling swimming kinematics and performance at a gait transition. J Exp Biol 199:2243-2252

Eckert GJ (1984) Annual and spatial variation in recruitment of labroid fishes among seven reefs in the Capricorn/ Bunker Group, Great Barrier Reef. Mar Biol 78:123-128

Eckert GJ (1985) Settlement of coral reef fishes to different natural substrata and at different depths. Proc 5th Int Coral Reef Congr 5:385-390 (Gabrié C, Harmelin VM [eds] Antenne Museum-EPHE, Moerea, French Polynesia) 
Freeman MF, Tukey JW (1950) Transformations related to the angular and the square root. Ann Math Statist 21:607-611

Fulton CJ, Bellwood DR (2002) Patterns of foraging in labrid fishes. Mar Ecol Prog Ser 226:135-142

Fulton CJ, Bellwood DR, Wainwright PC (2001) The relationship between swimming ability and habitat use in wrasses (Labridae). Mar Biol 139:25-33

Gerstner CL (1998) Use of substratum ripples for flow refuging by Atlantic cod, Gadus morhua. Environ Biol Fish 51: 455-460

Gerstner CL, Webb PW (1998) The station-holding performance of the plaice Pleuronectes platessa on artificial substratum ripples. Can J Zool 76:260-268

Green AL (1996) Spatial, temporal and ontogenetic patterns of habitat use by coral reef fishes (family Labridae). Mar Ecol Prog Ser 133:1-11

Hixon MA, Beets JP (1993) Predation, prey refuges and the structure of coral reef fish assemblages. Ecol Monogr 63: $77-101$

Jones GP (1991) Postrecruitment processes in the ecology of coral reef fish populations: a multifactorial perspective. In: Sale PF (ed) The ecology of fishes on coral reefs. Academic Press, Sydney, p 294-347

Mittelbach GG (1981) Foraging efficiency and body size: a study of optimal diet and habitat use by bluegills. Ecology 62:1370-1386

Munday PL (2000) Interactions between habitat use and patterns of abundance in coral-dwelling fishes of the genus Gobiodon. Environ Biol Fish 58:355-369

Munday PL, Jones GP, Caley MJ (1997) Habitat specialisation and the distribution and abundance of coral-dwelling gobies. Mar Ecol Prog Ser 152:227-239

Randall JE, Allen GR, Steene RC (1997) Fishes of the Great Barrier Reef and Coral Sea, 2nd edn. Crawford House Publishing, Bathurst

Russ GR (1984) Distribution and abundance of herbivorous grazing fishes in the central Great Barrier Reef. I. Levels of variability across the entire continental shelf. Mar Ecol Prog Ser 20:23-34

Sagnes PP, Gaudin B, Stanzer B (1997) Shifts in morphometrics and their relation to hydrodynamic potential and habitat use during grayling ontogenesis. J Fish Biol 50: 846-858

Editorial responsibility: Charles Birkeland (Contributing Editor), Honolulu, Hawaii, USA
Simonovic PD, Garner P, Eastwood EA, Kovac V, Copp GH (1999) Correspondence between ontogenetic shifts in morphology and habitat use in minnow Phoxinus phoxinus. Environ Biol Fish 56:117-128

Sokal RR, Rohlf FJ (1995) Biometry: the principles and practice of statistics in biological research, 3rd edn. WH Freeman \& Company, New York

Vogel S (1994) Life in moving fluids. Princeton University Press, Princeton, NJ

Wainwright PC, Bellwood DR, Westneat MW (1999) Pectoral fin diversity and evolution in labrid fishes. Am Zool 39:55A

Wainwright PC, Bellwood DR, Westneat MW (2002) Ecomorphology of locomotion in labrid fishes. Environ Biol Fish (in press)

Walker JA, Westneat MW (2000) Mechanical performance of aquatic rowing and flying. Proc R Soc Lond Ser B Biol Sci 267:1875-1881

Walker JA, Westneat MW (2002) Performance limits of labriform propulsion and correlates with fin shape and motion. J Exp Biol 205:177-187

Webb PW (1994) The biology of fish swimming. In: Maddock L, Bone Q, Rayner JMV (eds) Mechanics and physiology of animal swimming. Cambridge University Press, Cambridge, $\mathrm{p} 45-62$

Webb PW, Weihs D (1986) Functional locomotor morphology of early life history stages of fishes. Trans Am Fish Soc 115: $115-127$

Werner EE, Hall DJ (1988) Ontogenetic habitat shifts in bluegill: the foraging rate-predation risk trade-off. Ecology 69: 1352-1366

Werner EE, Gilliam JF, Hall DJ, Mittelbach GG (1983) An experimental test of the effects of predation risk on habitat use in fish. Ecology 64:1540-1548

Williams DM (1982) Patterns in the distribution of fish communities across the central Great Barrier Reef. Coral Reefs $1: 35-43$

Williams DM (1991) Patterns and processes in the distribution of coral reef fishes. In: Sale PF (ed) The ecology of fishes on coral reefs. Academic Press, Sydney, p 437-474

Winer BJ (1971) Statistical concepts in experimental design. McGraw-Hill, New York

Zar JH (1984) Biostatistical analysis, 2nd edn. Prentice-Hall, Englewood Cliffs, NJ

Submitted: July 7, 2001; Accepted: January 28, 2002

Proofs received from author(s): May 21, 2002 